\title{
Rock Slope Stability Research
}

\author{
J.R.L. Read CSIRO Exploration \& Mining, Australia
}

\begin{abstract}
The methods we use to describe the anisotropic strength of closely jointed rock masses are highly subjective and experiential. Consequently, there is a need to construct an 'equivalent material' that honours the strength of the intact rock and joint fabric within the rock bridges that may occur along a candidate failure surface in a closely jointed rock mass. We then need to be able to use this model to simulate the brittle fracture that can and does propagate across the joint fabric within the rock bridges as the rock mass deforms. It has been found that the Bonded Particle Method utilised by the Itasca PFC numerical modelling codes may be able to provide such a material model. Known as the Synthetic Rock Mass (SRM) model, the model represents the intact rock in the rock bridges with an assemblage of bonded particles and the joints by a sliding joint model that allows associated particles to slide through, rather than over, one another and so represent joints that slide and open in the normal way. In 3-D block caving simulations SRM rock bridge fracture has been found to be widespread. From a rock slope stability point of view the model has the potential to provide a means of developing a strength envelope that does not rely on either Mohr Coulomb or Hoek-Brown criteria. Similarly, the inverse of providing Hoek-Brown parameters and calibrating the HoekBrown strength envelope should also be possible. A rock mass characterisation program with numerical and empirical comparisons involving SRM test samples calibrated with intact rock and joint data coming from different mine sites has therefore been developed to test the concept in conjunction with studies to utilise the model in PFC and continuum/discontinuum codes for slope stability analysis purposes.
\end{abstract}

\section{Introduction}

Our approach to slope design and the methods we use to predict the performance of large rock slopes has changed little in the past 25 years. We have followed a process of creating a geotechnical model that describes the engineering properties of the rock mass and insert those properties into limiting equilibrium and numerical stability analyses that estimate factors of safety and probabilities of failure that we use to either accept or reject the design. Mostly our efforts are rewarded with success, but not always. Unpredicted failures do occur. Usually they are accompanied by the question, why? Did we simply get it wrong or were there flaws in the process? Sometimes we do just simply get it wrong. However and as much as we may not like to admit it, there are some basic flaws in the process which do limit our ability to be totally confident in our predictions. Identifying and overcoming these flaws is a research objective that is outlined in this paper.

\section{Rock slope stability analyses}

In general, rock slope stability analyses can be divided into two categories: those directed at assessing the likelihood of structurally controlled, kinematically possible failures such as plane failures, wedge failures, and toppling failures; and those that attempt to assess the likelihood of a failure occurring through the rock mass. All of these analyses utilise the Mohr Coulomb failure criterion. This is acceptable for the kinematically possible failures, but introduces difficulties in closely jointed rock masses. Why?

Rock slope stability design efforts commenced during the 1950s and 1960s and were based on soil mechanics experience and methodology. They incorporated assumptions of scale and discontinuity density such that the size of the rock particles in a high, closely jointed rock slope were considered to be equivalent to an isotropic mass of soil particles. This assumption enabled the direct use of the emerging limiting equilibrium slope failure analyses such as Bishop, Janbu, Morgenstern \& Price and Spencer. In the process a basic need to deliver friction $(\varnothing)$ and cohesion (c) values for the rock mass was created, which has carried over into all of the more recently developed continuum and discontinuum numerical modelling tools we commonly use in slope stability analysis. 
As mentioned, there are some basic flaws in this process, two in particular. Firstly, Mohr Coulomb measures friction and cohesion at a point, which we transfer to our three-dimensional body of rock by assuming that the rock mass is isotropic, which in a jointed rock mass is not the case. Secondly, obtaining friction and cohesion values for a closely jointed rock mass is difficult, mostly because triaxial testing of representative rock mass samples is itself made difficult by the complexity of performing tests on rock at a scale that is of the same order of magnitude as the real thing. Sample disturbance and equipment size are other major limitations. Consequently, the preferred method has been to derive empirical values of friction and cohesion from rock mass classification schemes that have been calibrated from experience.

There are many different rock mass classification schemes, but in rock slope engineering today the most used schemes are:

- Bieniawski’s Rock Mass Rating (RMR) scheme (Bieniawski, 1976, 1989), which originally was introduced for tunnelling and civil engineering applications.

- Laubscher's Rock Mass Rating (IRMR and MRMR) schemes (Laubscher, 1990; Laubscher and Jakubec, 2001).

- Hoek \& Brown's Geological Strength Index (GSI) (Hoek, 1983; Hoek et al., 2002).

The empirical friction and cohesion values that can be derived from these schemes are subject to a number of idiosyncrasies and limitations. RQD, which is embodied in all three of the schemes, provides a good example of why. Introduced by Deere and his co-workers in 1967 (Deere et al., 1967), RQD is an index of rock quality in that problematic rock that is highly weathered, soft, fractured, sheared, and jointed is counted against the rock mass. In other words, as introduced it is simply a measurement of the percentage of 'good' rock recovered from an interval of the borehole (Deer and Deere, 1988). As a parameter however, which is how it has become to be used, it is poorly defined. It is highly subjective and inconsistent, with different operators frequently reporting different values for the same intervals of core, and often provides inaccurate and misleading results. A particular source of error that specifically leads to this situation is that the value of $100 \mathrm{~mm}$ of unbroken rock on which the measure is based is an arbitrary and abrupt boundary; small differences in joint spacing can produce large differences in the RQD value. For example, for a rock mass with a joint spacing of $90 \mathrm{~mm}$ perpendicular to the borehole, RQD $=0 \%$, while for a joint spacing of $110 \mathrm{~mm}, \mathrm{RQD}=100 \%$. Similarly, RQD can be biased by the orientation of the borehole or scan line with respect to the joint orientation. In these cases the apparent change in the joint spacing created by measuring from a different direction can again produce a large difference in the RQD value ( $0 \%$ to $100 \%)$.

Introduced in 1995 (Hoek et al., 1995) to replace Bieniawski RMR in the generalised Hoek-Brown criterion, the concept of the 'Geological Strength Index' (GSI), recognised the difficulties encountered by the criterion when the value of RMR was less than 25. Principal benefits claimed for the GSI concept (versus Bieniawski RMR) were that it was based more heavily on fundamental geological observation and less on 'numbers' as featured by RMR. By sidestepping RMR it was said to avoid double counting of joint spacing, which features within the expressions for both RQD and RMR, and avoid double counting of UCS, which features within the expressions for both RQD and the generalised Hoek-Brown criterion.

The benefits claimed are however, somewhat cosmetic. Fundamental geological observation is accentuated, but the charted GSI values (Hoek et al., 1995, Table 8.4, and all subsequent charts) are still those of Bieniawski RMR (1976). It follows that joint spacing remains double counted, UCS remains double counted, and we have not avoided the uncertainties of RQD as a parameter when determining rock mass strength.

From every viewpoint therefore, there is a high level of uncertainty in the realism of the derived friction (Ø) and cohesion (c) values, which requires us to calibrate $\varnothing$ and c against existing slope performance data. Furthermore, the $\varnothing$ and c values we do use are applied as 'smeared' or 'average', non-directional parameters across the 'intact' pieces of rock (rock bridges) that occur between the structural defects that cut through the rock mass. We are unable to simulate the brittle fracture that can and does propagate across the joint fabric within these pieces of rock as stress relaxation enables the structured rock mass to dilate and the pieces to separate and move about. And we are unable to account for the effect of the degree of disturbance to which the rock mass has been subjected by stress relaxation on the strength of the rock mass (the ' $\mathrm{D}$ ' factor in the Hoek-Brown strength criterion, Hoek et al., 2002). 


\section{$3 \quad$ Research needs}

The limitations of our current methods of analysis underpin three main research needs (Read, 2007):

1. There is a need to construct an 'equivalent material' that honours the strength of the intact rock and joint fabric within the rock bridges that may occur along a candidate failure surface in a closely jointed rock mass.

2. We need to be able to simulate the brittle fracture that can and does propagate across the joint fabric within the rock bridges as the rock mass deforms.

3. We need to critically assess the possibility that the strength of a dilating rock mass and its constituent pieces of mobile rock is a function of particle interlock or some other energy function rather than particle friction ( $\varnothing$ and c) as dictated by the Mohr Coulomb failure criterion. Do we need to define a rock mass strength at all? For example, for a structure or set of unfavourably oriented structures of given shear strength and persistence, combined with the intact rock strength, pore pressure and stress, is it possible to determine the likelihood of a slope failing without having to estimate the strength of the rock mass strength at all?

These requirements and questions are being addressed by a research project known as the Large Open Pit (LOP) Project which was instigated in 2004 with the objective of reassessing the fundamentals of rock mass strength and slope failure mechanisms from first principles (Read and Ogden, 2006). The project was instigated with the support of a number of international mining companies, research organisations and professionals with interests in open pit mining and is committed to bringing the outcomes of the research into the public domain.

\section{Research actions}

A number of approaches and numerical codes with the potential to construct an 'equivalent material' and model brittle fracture across the rock bridges were considered. Two principal candidates emerged, Itasca's PFC codes and Rockfield Software Limited's ELFEN code. After due consideration at a project numerical modelling workshop when trial slope stability analyses were studied, the Itasca PFC code was selected for further study. The principle reason for this decision was that ELFEN, although capable of modelling brittle fracture, requires a macro mechanics based fracture criterion such as Mohr Coulomb to determine if a crack is to be created within a continuum element. On the other hand, PFC uses a micro mechanics based criterion for this task, which offered the potential for stepping away from the Mohr Coulomb criterion, a feature that was consistent with the objectives of the research.

In PFC the entire model is composed from the start as discrete elements bonded together (the Bonded Particle Method [BPM], Potyondy \& Cundall, 2004), with the inputs (microproperties) restricted to stiffness and strength parameters for the particles and bonds. The initial state of such a bonded assembly of particles is then taken to be equivalent to an elastic continuum. The fracturing process consists of individual bonds breaking (micro-cracking) and coalescing to form macro-cracks. The PFC assembly thus is said to exhibit a rich constitutive behavior as an emergent property of the particle assembly without the use of supplied macro-mechanics constitutive models. Extensive tests on simulated laboratory samples have shown that the synthetic 'PFC material' can be calibrated to produce quantitative fits to almost all measured physical parameters, including moduli, strengths and fracture toughness (Potyondy and Cundall, 2004).

Development of the BPM method since 2004 performed for block caving studies by Itasca for the international Mass Mining Technology (MMT) Project has shown that it is possible to use the BPM method to represent the strength of the intact rock and joint fabric within the rock bridges with an 'equivalent material' or Synthetic Rock Mass (SRM) model. In this model the intact rock is represented by an assemblage of bonded particles numerically calibrated using UCS, Modulus and/or Poisson's Ratio values to those measured for an intact sample. The joints are represented by a sliding joint model that allows associated particles to slide through, rather than over, one another and so represent joints that slide and open in the normal way (Pierce et al., 2007). In 3-D block caving simulations performed for the MMT Project, SRM rock bridge fracture has been found to be widespread. 
From a slope stability point of view the SRM rock bridge is a potential break through. If it can be shown that that the SRM does honour the strength of the intact material and the joint fabric within the rock bridges along a candidate failure surface in a closely jointed rock mass, then it provides a possible means of developing a strength envelope that does not rely on either Mohr Coulomb and/or Hoek-Brown criteria. Similarly, the inverse of providing Hoek-Brown parameters and calibrating the Hoek-Brown strength envelope should also be possible.

In following through on these possibilities, two problems, those of scale and run time, were first addressed. It was uncertain whether the PFC codes were capable of representing closely jointed rock slopes with the resolution required for a large pit slope. It was recognised by Itasca that it is not yet possible to model a full 3-D slope at the same resolution as in 2-D. It was also known that, because of run times, PFC3-D could only handle SRM rock bridges with maximum dimensions of the order of $12 \mathrm{~m}$. The first action was therefore to test a PFC2-D model of a large pit slope in closely jointed rock. For this test a $500 \mathrm{~m}$ high, $1000 \mathrm{~m}$ wide slope from an LOP sponsor's mine site was described. A discrete fracture modelling (DFN) process was then used by Itasca to introduce eight faults with trace lengths of between 74 to $532 \mathrm{~m}$ and spacings of $15 \mathrm{~m}$ to $140 \mathrm{~m}$, together with two joints sets with lengths of $15.5 \mathrm{~m}$ and spacings of $5 \mathrm{~m}$ into the model. This resulted in a 2-D slope containing 2890 faults and 37,335 joints for a total of 40,225 discontinuities. These required approximately 330,000 particles, which were combined in 38,656 blocks or 'clusters'; a cluster is defined as a group of particles, each of which may be reached from any other in the group without crossing a joint face (Cundall, 2007).

The outcome of the test was progressive failure with toppling and sliding along major faults and yielding and dislocation of smaller blocks of rocks (rock bridges) to depths of up to $130 \mathrm{~m}$, but no rock bridge fracturing. The lack of rock bridge fracturing was thought likely to be a 2-D artefact, with the intersecting structures forming many discrete blocks or closed areas in 2-D. This is thought unlikely to happen in 3-D, when the structures probably will not form closed volumes. It did not happen in 3-D block caving simulations performed by Itasca for the MMT Project, where rock bridge fracture was found to be widespread (Cundall, 2007). Conversely however, it may also represent reality, with the rock mass failure happening entirely along sets of unfavourably oriented structures.

Either way the outcomes of the LOP Project PFC2-D trial and the MMT Project 3-D SRM rock bridge block caving studies have been brought together into two principal ongoing LOP Project research tasks. The work is being performed collaboratively by Itasca and CSIRO under the leadership and technical direction of $\mathrm{Dr}$ Peter Cundall.

The first task is a detailed rock mass characterisation program with numerical and empirical comparisons involving SRM test samples calibrated with intact rock and joint data coming from LOP sponsor's mine sites. The program involves using data from a selected volume of rock to test numerically and derive an 'equivalent material' SRM strength envelope from which the Hoek-Brown parameters can be derived and compared with those estimated in the field using the GSI approach. The scale of the initial tests is $20 \mathrm{~m}$, that is, bench scale. Three data sets involving three different rock types from each sponsor are involved.

Given that a full 3-D slope model is not possible, the second task is exploring whether it is possible to uplift the 'equivalent material' SRM strength envelope into a continuum and/or discontinuum code such as FLAC3-D, ELFEN or ABACUS and instigate a 'hybrid' approach where there is an iterative application of the continuum code for the response of the entire rock mass and a particle code (PFC3-D) for the response of the equivalent material. The approach has been trialled successfully by Itasca in the MMT Project block caving studies, with the SRM shown to honour the strength of the intact material and the joint fabric within the rock bridges during caving (Cundall, 2007). Hence, it is reasonable to expect that it can be adapted to an open pit slope. Accordingly, a 2-D slope example is being set up in PFC2-D with a DFN pattern selected such that both intact rock fracture and joint sliding/opening must occur for failure. In parallel, a hybrid model using FLAC for the continuum slope model and PFC2-D for the element testing environment for the given DFN is being constructed. Both models will be exercised, with an iterative approach applied for the hybrid model. The results of the two models will then be compared and documented.

If Task 2 is successful, a 3-D hybrid model will be constructed to demonstrate that the approach is viable in 3-D. If Task 2 is not successful, ways and means of improving the speed of a full PFC3-D simulation, that is, one that contains explicit jointing, will be explored. Judicious use of the Adaptive Continuum/Discontinuum 
(AC/DC) option developed by Itasca, which would take the outer regions of the model to be unjointed and elastic and replace the particles in them with a stiffness model, could help to model larger problems. Actual simulations of rock slope failures will be required to determine the feasibility of this approach and the size of problem that could be addressed with the help of AC/DC.

\section{Acknowledgements}

The author wishes to acknowledge the support of the LOP Project Sponsors Management Committee for the research outlined in this paper and their dedication to bringing a better understanding of rock mass strength and the mechanisms of slope failure in closely jointed rock into the public domain. The LOP Project sponsors are: Anglo American plc; Barrick Gold Corporation; BHP Billiton Innovation Pty Limited; Corporacion Naciónal Del Cobre De Chile ('Codelco'); Compania Minera Dona Inès de Collahuasi SCM ('Collahuasi'); DeBeers Group Services (Pty) Limited; Newcrest Mining Limited; Newmont Australia Limited; Xstrata Queensland Limited; Debswana Diamond Company; and the RioTinto Group.

Additionally, the essential part played by Dr Peter Cundall, Itasca Consulting Group, Inc. (Itasca), and his associates in developing new SRM approaches to the fundamentals of rock mass strength together with the permission of the MMT Project sponsors for the LOP Project to use and further develop background intellectual property developed by Itasca for the MMT Project using funding provided by the MMT Project sponsors is gratefully acknowledged.

\section{References}

Bieniawski, Z.T. (1976) Rock mass classification in Rock Engineering Applications. In Exploration for Rock Engineering: Proc. of the Symposium, Johannesburg, 1, pp. 97-106. A.A. Balkema, Rotterdam.

Bieniawski, Z.T. (1989) Engineering Rock Mass Classifications. John Wiley \& Sons, 251 p.

Cundall, P.A. (2007) PFC modelling of large slopes in brittle, jointed rock. Confidential LOP Project Report, unpublished, $10 \mathrm{p}$.

Deere, D.U. and Deere, D.W. (1988) The Rock Quality Designation (RQD) Index in Practice. Rock Classification Systems for Engineering Purposes, ASTM STP 984, pp. 91-101.

Deere, D.U., Hendron A.J., Patton, F.D. and Cording, E.J. (1967) Design of Surface and Near-Surface Construction in Rock. SME, 1967, Failure \& Breakage of Rock, pp. 237-302.

Hoek, E. (1983) Strength of Jointed Rock Masses. 23rd Rankine Lecture. Geotechnique, XXXIII, pp. 185-223.

Hoek, E., Kaiser, P.K. and Bawden, W.F. (1995) Support of Underground Excavations in hard Rock. Mining Research Directorate \& Universities Research Incentive Fund, Canada, 215p.

Hoek, E., Carranza-Torres, C. and Corkum, B. (2002) Hoek-Brown Failure Criterion - 2002 Edition. Proc. North American Rock Mech. Soc., Toronto, July 2002, 7 p.

Laubscher, D.H. (1990) A geomechanics classification system for the rating of rock mass in mine design. J. S. Afr. Inst. Metall., 90 (10), pp. 267-273.

Laubscher, D.H. and Jakubec, J. (2001) The MRMR rock mass classification for jointed rock masses. Underground Mining Methods. Engineering Fundamentals and International Case Studies, W.A. Hustrulid and R.L. Bullock (editors), Society of Mining Engineers, AIME: New York, pp. 474-481.

Pierce, M. Cundall, P. and Potyondy, D. (2007) A synthetic rock mass model for jointed rock. 1st Canada-U.S. Rock Mechanics Symposium, Vancouver, B.C., May 27-31, 2007, pp. 341-349.

Potyondy, D.O. and Cundall, P.A. (2004) A bonded particle model for rock. Int. J. Rock Mechanics \& Mining Sciences, 41, pp. 1329-1364.

Read, J.R.L (2007) Predicting the behaviour and failure of large rock slopes. 1st Canada-U.S. Rock Mechanics Symposium, Vancouver, B.C., May 27-31, 2007, pp. 1237-1243.

Read, J.R.L. and Ogden, A.N. (2006) Developing New Approaches to Rock Slope Stability Analyses. Int. Symposium on the Stability of Rock Slopes in Open Pit Mining and Civil Engineering Situations, Cape Town, South Africa. SAIMM, Symposium Series S44, pp. 3-10. 